\title{
The Role of CK20, p53 and p63 in Differentiation of Some Urothelial Lesions of Urinary Bladder, Immunohistochemical Study
}

\author{
Sayed Abdel Raheem, Abdel Naby Saied, Rabee Al Shaer, Osama Mustafa, \\ Ali Hassan Ali \\ Departments of Pathology and Anatomy, Faculty of Medicine, Al Azhar University, Cairo, Egypt \\ Email: sayedabdelrahim8@gmail.com
}

Received 5 June 2014; revised 4 July 2014; accepted 28 July 2014

Copyright (C) 2014 by authors and Scientific Research Publishing Inc.

This work is licensed under the Creative Commons Attribution International License (CC BY).

http://creativecommons.org/licenses/by/4.0/

(c) (i) Dpen Access

\section{Abstract}

Background: Differentiation of urothelial hyperplasia, dysplasia and carcinoma in situ (CIS) may pose diagnostic difficulties. We aim to evaluate the role of CK20, p53 and p63 in differentiation of such lesions. Methods: we evaluate these markers in 213 cases of bladder lesions (14 hyperplasia, 7 dysplasia, 5 CIS, 25 noninvasive and 162 invasive urothelial carcinoma) in a retrospective study on sections from formalin-fixed, paraffin-embedded blocks. Cytoplasmic staining considered for CK20 and nuclear staining for $\mathrm{p53}$ and p63. Results: CK20 was expressed in 14 out of 14 hyperplasia (4 strong, 7 moderate, 3 weak), in 7 out of 7 dysplasia (4 strong, 3 moderate), in 5 out of 5 CIS, in 19 out of 25 noninvasive carcinoma; strong in 11 (7 low grade, 4 high grade), moderate in 7 (5 low grade, 2 high grade), and weak in 1 case of low grade, in 136 out of 162 invasive carcinoma; strong in 46 ( 22 grade II, 24 grade III), moderate in 71 ( 2 grade I, 58 grade II, 11 grade III), and weak in 19 ( 2 grade I, 15 grade II, 2 grade III), no expression in 2 cases of grade IV. p53 was expressed in 7 out of 14 hyperplasia (weak in all cases), in 7 out of 7 dysplasia (5 strong, 2 moderate), in 5 out of 5 CIS (strong in all cases), in 20 out of 25 noninvasive carcinoma (8 strong, 9 moderate, 3 weak), in 135 out of 162 invasive carcinoma (34 strong, 73 moderate, 28 weak). p63 was expressed in 14 out of 14 hyperplasia, in 7 out of 7 dysplasia, in 4 out of 5 CIS, in 25 out of 25 noninvasive carcinoma, and in 134 out of 162 invasive carcinoma (28 strong, 63 moderate, 43 weak). CK20 was insignificant in noninvasive and significant in invasive carcinoma, while p53 and p63 were significant in noninvasive and invasive carcinoma. Conclusion: CK20, p53 and p63 are useful in differentiation of different bladder lesions. 


\section{Keywords}

\section{Urothelial Lesions, CK20, p53, p63}

\section{Introduction}

Urothelial carcinoma is the 7th most common cancer worldwide [1]. More than 50\% of patients with non-invasive urothelial tumors have recurrences (or new occurrences), and $10 \%$ to $15 \%$ of these will progress to invasive cancer [2]. The most important predictive parameter for the biological behavior of urothelial carcinoma, except depth of invasion, is the histological grade of tumor [3], although tumor grade and stage have been shown to have a strong correlation with tumor recurrence and progression to invasive bladder cancer [4]. A large number of markers have been extensively investigated as potential predictors of bladder tumor recurrence, progression, or response to therapy [2]. CK20 belongs to the epithelial subgroup of cytoskeleton-associated intermediate filaments. It has been suggested that CK20 may be an important tool for detecting and identifying these types of cancer (urothelial carcinoma) and may be used as a potential predictors of bladder tumor recurrence, progression, or response to therapy [5]. Mutated p53 gene is a common genetic abnormality in urothelial carcinoma of the bladder. Some studies have depicted that over expression of p53 occurs in higher stages and grades of urothelial carcinoma and over expression of the p53 gene product has been reported as a marker of progression in urothelial carcinoma [6]. p63, a member of the p53 gene family, encodes multiple proteins that may either transactivate p53 responsive genes or act as a dominant-negative factor toward p53. p63 is regulated in bladder carcinogenesis and p63 expression is lost in most invasive cancers whereas non invasive tumors maintain p63 expression [7]. CK20, p53 and p63 immunohistochemistry is suggested to be helpful to distinguish dysplastic changes and carcinoma in situ from reactive atypia [8] [9].

\section{Material and Methods}

This work included 213 cases of different bladder lesions collected from Al-Azhar Faculty of Medicine Hospital labs during the period from January 2005 to January 2010; 43 radical cystectomies and 170 cystoscopic biopsies, 8 cases of normal urothelium included as a control. Four micron thick sections were cut from paraffin blocks of all cases and stained with haematoxylin and eosin ( $\mathrm{H} \& \mathrm{E}$ ). All cases were re-evaluated; graded and staged according to WHO classification 2004 of bladder tumors and TNM staging 2009 respectively. For immunohistochemistry, sections were taken on poly-L-lysine coated slides. The primary antibodies were as follows: CK20 (Monoclonal mouse anti human cytokeratin 20, Dako cooperation Denmark; colonic carcinoma as positive control \& tumor stroma as negative control), p53 (Monoclonal mouse anti human p53, Lab Vision Cooperation Fremount USA; Breast cancer as positive control \& normal liver tissue as negative control), p63 (Monoclonal mouse anti human p63, Biocare Medical Cooperation Concord USA; normal prostate as positive control \& muscle tissue as negative control). Cytoplasmic staining was considered for CK20 and nuclear staining for p53 and p63. According to Yildiz's et al., (2009) [10], CK20 cytoplasmic staining was evaluated: (0; no staining), (1+; patchy or/and weak), $(2+;<50 \%$ cells, moderate), (3+; $>50 \%$ cells, strong). p53 was evaluated according to number of positive cells ( 0 ; no staining), ( $1+;<15 \%$ cells, weak), ( $2+; 15 \%-50 \%$ cells, moderate), (3+; >50\% cells, strong). According to Kaufmann's et al. (2001) [11], p63 was evaluated according to the percentage of positive cells, (1+; $1 \%-10 \%),(2+; 11 \%-50 \%)$, and (3+; more than $50 \%)$.

\section{Statistical Analysis}

Statistical presentation and analysis of the present study was conducted, using the mean, standard error, student t-test and Chi-square by SPSS V17.Statistical significance was established as $\mathrm{P}<0.05$ [12] [13].

\section{Results}

This study consisted of 213 cases of bladder lesions and 8 cases of normal urothelium as a control. The age of the patients ranged from 29 to 84 years (mean: 59.4) with 204 males and 9 females.

Histopathological findings: 
Urothelial hyperplasia (14 cases): of flat and papillary types, and associating different types of cystitis (6 bilharzial, 5 polypoid, 1 interstitial, 1 lymphoid and 1 hemorrhagic) (see Figure 1).

Urothelial dysplasia (7 cases): with variable loss of polarity, irregular nuclear borders, inconspicuous nucleoli and rare mitoses, moderate in 5 cases and severe in 2 cases.

Urothelial CIS (5 cases): associating invasive carcinoma, showing high grade nuclear anaplasia, large pleomorphic nuclei, frequent mitoses, and involving the entire epithelial thickness (see Figure 2).

Urothelial carcinoma (187 cases): According to WHO classification (2004), 25 cases of non invasive papillary carcinoma (18 low grade and 7 high grade) and according to TNM staging (2009), all cases staged as pTa, and 162 cases of invasive urothelial carcinoma (8 grade I, 111 grade II, 41 grade III and 2 grade IV), and staged as (69 pT1, 62 pT2, 26 pT3, 5 pT4) (see Table 1 \& Figure 3).

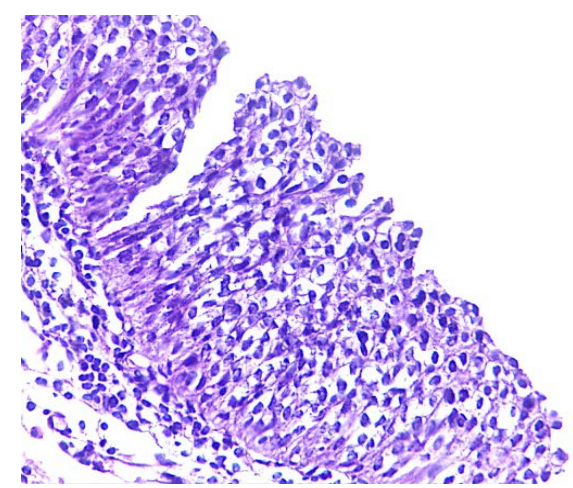

Figure 1. Urothelial hyperplasia showing benign-looking hyperplastic urothelium (H \& E × 200).

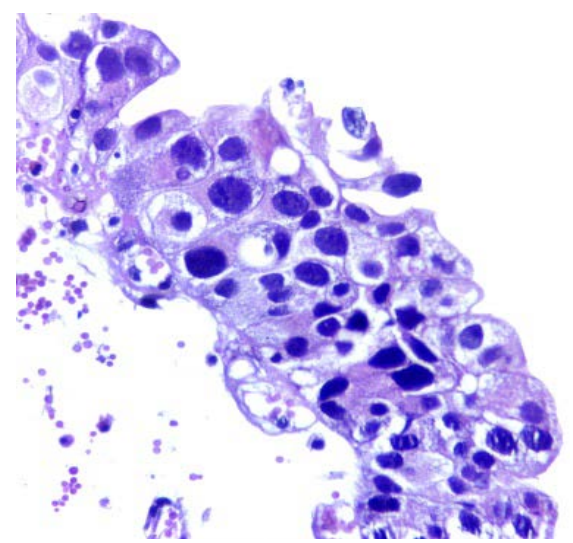

Figure 2. Urothelial CIS showing replacement of urothelium by malignant cells with nuclear anaplasia, with no invasion (H \& E × 400).

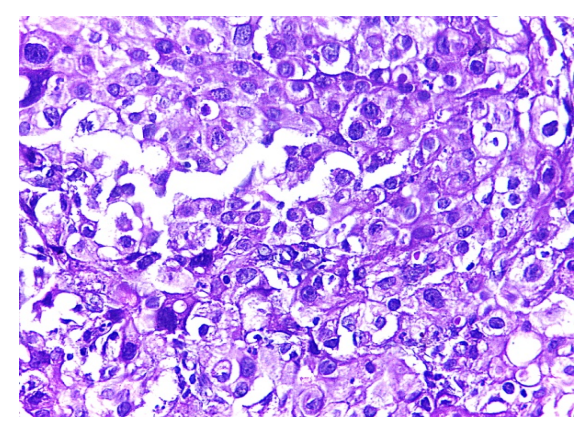

Figure 3. Invasive urothelial carcinoma grade III showing groups of malignant urothelial cells with marked anaplasia (H \& E × 360). 
Table 1. Grading and staging of the studied invasive urothelial carcinomas.

\begin{tabular}{|c|c|c|c|c|c|c|}
\hline \multirow{2}{*}{ Sta } & & \multicolumn{5}{|c|}{ Grade (Invasive Carcinoma) } \\
\hline & & Grade I & Grade II & Grade III & Grade IV & Total \\
\hline \multirow{2}{*}{ pT1 } & $\mathrm{N}$ & 8 & 59 & 2 & 0 & 69 \\
\hline & $\%$ & 4.94 & 36.42 & 1.23 & 0.00 & 42.59 \\
\hline \multirow{2}{*}{ pT2 } & $\mathrm{N}$ & 0 & 44 & 16 & 2 & 62 \\
\hline & $\%$ & 0.00 & 27.16 & 9.88 & 1.23 & 38.27 \\
\hline \multirow{2}{*}{ pT3 } & $\mathrm{N}$ & 0 & 8 & 18 & 0 & 26 \\
\hline & $\%$ & 0.00 & 4.94 & 11.11 & 0.00 & 16.05 \\
\hline \multirow{2}{*}{ pT4 } & $\mathrm{N}$ & 0 & 0 & 5 & 0 & 5 \\
\hline & $\%$ & 0.00 & 0.00 & 3.09 & 0.00 & 3.09 \\
\hline \multirow{2}{*}{ Total } & $\mathrm{N}$ & 8 & 111 & 41 & 2 & 162 \\
\hline & $\%$ & 4.94 & 68.52 & 25.31 & 1.23 & 100.00 \\
\hline \multirow{2}{*}{ Chi-square } & $\mathrm{X}^{2}$ & & & 75.838 & & \\
\hline & P-value & & & 0.000 & & \\
\hline
\end{tabular}

\section{Immunohistochemical findings:}

CK20

Normal urothelium (8 cases): CK20 was expressed in all cases and localized to the superficial umbrella cell layer (strong in 1, moderate in 5 and weak in 2).

Urothelial Hyperplasia (14 cases): CK20 was expressed in all cases and limited to the superficial umbrella cell layer (strong in 4, moderate in 7 and weak in 3).

Urothelial Dysplasia (7 cases): CK20 was expressed in all cases, in upper 2/3 of urothelium in 6 cases (strong in 4 and moderate in 2), and moderate throughout the uroithelium in 1case, (see Figure 4). Urothelial CIS (5 cases): CK20 was strongly expressed throughout the urothelium in all cases.

Non-invasive papillary carcinoma (25 cases): CK20 was expressed in 19 cases (76\%), strong in 11 (44\%), moderate in 7 (28\%) and weak in 1 (4\%), (see Table 2 \& Figure 5).

Invasive urothelial carcinoma (162 cases): CK20 was expressed in 136 cases (84\%), strong in 46 (28.4\%), moderate in 71 (43.9\%) and weak in 19 (11.7\%), (see Table 3, Table 4 and Figure 6).

p53

Normal urothelium (8 cases): p53 was expressed in 3 cases (37.5\%; seen in basal and intermediate layers) while the other 5 cases showed no reactivity.

Urothelial hyperplasia (14 cases): p53 was expressed in 7 (50\%; seen in basal and intermediate layers) while the other 7 cases showed no reactivity.

Urothelial Dysplasia (7 cases): p53 was expressed throughout the urothelium in all cases (strong in 5 and moderate in 2).

Urothelial CIS (5 cases): p53 was expressed throughout the urothelium in all cases, (see Figure 7).

Non-invasive papillary carcinoma (25 cases): p53 was expressed in 20 cases (80\%), strong in 8 (32\%), moderate in 9 (36\%) and weak in 3 (12\%), (see Table 5 \& Figure 8).

Invasive urothelial carcinoma (162 cases): p53 was expressed in 135 cases (83.33\%), strong in 34 (20.99\%), moderate in 73 (45.06\%) and weak in 28 (17.28\%), (see Table 6 \& Table 7).

p63

Normal urothelium (8 cases): p63 was strongly expressed in basal and intermediate layers of all cases while the superficial umbrella cells showed no reactivity.

Urothelial Hyperplasia (14 cases): p63 was strongly expressed in basal and intermediate layers of all cases while the superficial umbrella cells showed no reactivity.

Urothelial Dysplasia (7 cases): p63 was expressed in all cases; strong in basal layers with gradual decrease towards the epithelial surface. 


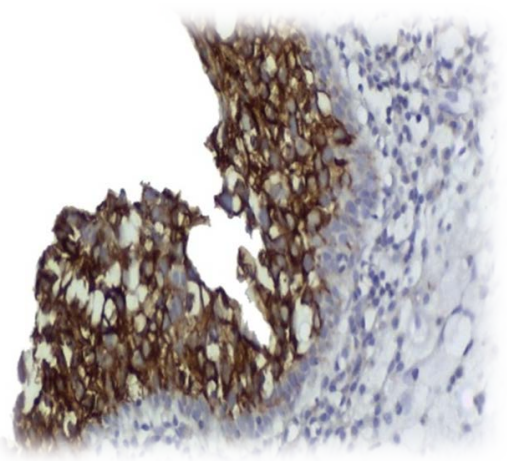

Figure 4. Urothelial dysplasia strongly positive for CK20, and positivity was seen in upper $2 \backslash 3$ of urothelium $(\mathrm{DAB} \times 235)$

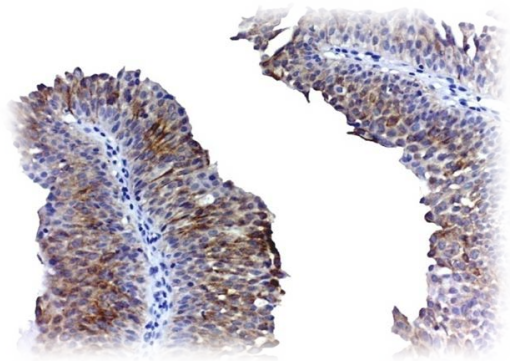

Figure 5. Low-grade non-invasive papillary urothelial carcinoma moderately positive for CK20 (DAB × 200).

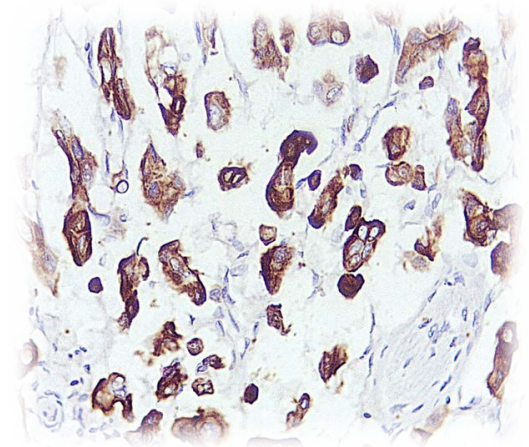

Figure 6. Invasive urothelial carcinoma grade III strongly positive for CK20 $(\mathrm{DAB} \times 400)$.

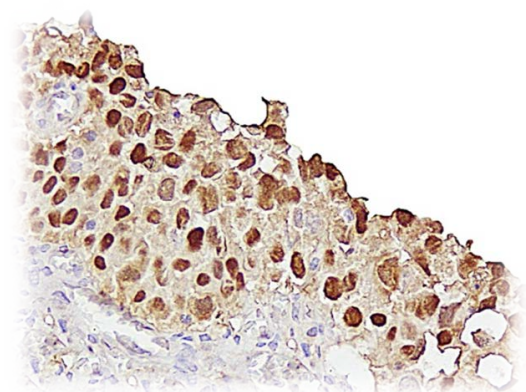

Figure 7. Urothelial CIS strongly positive for p53 and positivity was seen throughout urothelial thickness $(\mathrm{DAB} \times 235)$. 


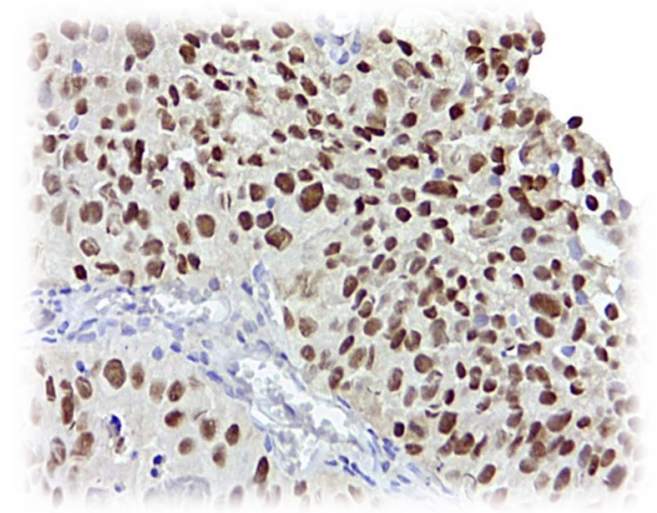

Figure 8. High grade non-invasive papillary urothelial carcinoma strongly positive for P53 (DAB $\times$ 235).

Table 2. Correlation of CK20 immunoreactivity to tumor grade of non-invasive papillary urothelial carcinoma.

\begin{tabular}{|c|c|c|c|c|c|c|}
\hline \multirow{2}{*}{\multicolumn{2}{|c|}{ Tumor grade }} & \multicolumn{5}{|c|}{ CK20 } \\
\hline & & Negative & Weak & Moderate & Strong & Total \\
\hline \multirow{2}{*}{ Low grade } & $\mathrm{N}$ & 5 & 1 & 5 & 7 & 18 \\
\hline & $\%$ & 28 & 6 & 28 & 39 & 100 \\
\hline \multirow{2}{*}{ High grade } & $\mathrm{N}$ & 1 & 0 & 2 & 4 & 7 \\
\hline & $\%$ & 14 & 0 & 29 & 57 & 100 \\
\hline \multirow{2}{*}{ Total } & $\mathrm{N}$ & 6 & 1 & 7 & 11 & 25 \\
\hline & $\%$ & 24 & 4 & 28 & 44 & 100 \\
\hline \multirow{2}{*}{ Chi-square } & $\mathrm{X}^{2}$ & & & 1.445 & & \\
\hline & P-value & & & 0.695 & & \\
\hline
\end{tabular}

Statistically insignificant (P-value: 0.695). So, CK20 expression is different in low and high grades of non-invasive papillary urothelial carcinoma.

Table 3. Correlation of CK20 immunoreactivity to tumor grade of invasive urothelial carcinoma.

\begin{tabular}{|c|c|c|c|c|c|c|}
\hline \multicolumn{2}{|c|}{ Grade } & \multicolumn{5}{|c|}{ CK20 } \\
\hline & & Negative & Weak & Moderate & Strong & Total \\
\hline \multirow{2}{*}{ Grade I } & $\mathrm{N}$ & 4 & 2 & 2 & 0 & 8 \\
\hline & $\%$ & 50.00 & 25.00 & 25.00 & 0.00 & 100.00 \\
\hline \multirow{2}{*}{ Grade II } & $\mathrm{N}$ & 16 & 15 & 58 & 22 & 111 \\
\hline & $\%$ & 14.41 & 13.51 & 52.25 & 19.82 & 100.00 \\
\hline \multirow{2}{*}{ Grade III } & $\mathrm{N}$ & 4 & 2 & 11 & 24 & 41 \\
\hline & $\%$ & 9.76 & 4.88 & 26.83 & 58.54 & 100.00 \\
\hline \multirow{2}{*}{ Grade IV } & $\mathrm{N}$ & 2 & 0 & 0 & 0 & 2 \\
\hline & $\%$ & 100.00 & 0.00 & 0.00 & 0.00 & 100.00 \\
\hline \multirow{2}{*}{ Total } & $\mathrm{N}$ & 26 & 19 & 71 & 46 & 162 \\
\hline & $\%$ & 16.05 & 11.73 & 43.83 & 28.40 & 100.00 \\
\hline \multirow{2}{*}{ Chi-square } & $\mathrm{X}^{2}$ & & & 39.017 & & \\
\hline & P-value & & & $<0.001^{*}$ & & \\
\hline
\end{tabular}

Statistically significantly (P value: $<0.001$ ). So, CK20 expression had a direct correlation with grade of invasive urothelial carcinoma. 
Table 4. Correlation of CK20 immunoreactivity to tumor stage of invasive urothelial carcinoma.

\begin{tabular}{|c|c|c|c|c|c|c|}
\hline \multirow{2}{*}{\multicolumn{2}{|c|}{ Tumor stage }} & \multicolumn{5}{|c|}{ CK20 } \\
\hline & & Negative & Weak & Moderate & Strong & Total \\
\hline \multirow{2}{*}{ Stage Ta } & $\mathrm{N}$ & 6 & 1 & 7 & 11 & 25 \\
\hline & $\%$ & 24.00 & 4.00 & 28.00 & 44.00 & 100.00 \\
\hline \multirow{2}{*}{ Stage T1 } & $\mathrm{N}$ & 13 & 11 & 39 & 6 & 69 \\
\hline & $\%$ & 18.84 & 15.94 & 56.52 & 8.70 & 100.00 \\
\hline \multirow{2}{*}{ Stage T2 } & $\mathrm{N}$ & 9 & 7 & 25 & 21 & 62 \\
\hline & $\%$ & 14.52 & 11.29 & 40.32 & 33.87 & 100.00 \\
\hline \multirow{2}{*}{ Stage T3 } & $\mathrm{N}$ & 4 & 1 & 7 & 14 & 26 \\
\hline & $\%$ & 15.38 & 3.85 & 26.92 & 53.85 & 100.00 \\
\hline \multirow{2}{*}{ stage T4 } & $\mathrm{N}$ & 0 & 0 & 0 & 5 & 5 \\
\hline & $\%$ & 0.00 & 0.00 & 0.00 & 100.00 & 100.00 \\
\hline \multirow{2}{*}{ Total } & $\mathrm{N}$ & 32 & 20 & 78 & 57 & 187 \\
\hline & $\%$ & 17.11 & 10.70 & 41.71 & 30.48 & 100.00 \\
\hline \multirow{2}{*}{ Chi-square } & $\mathrm{X}^{2}$ & & & 43.840 & & \\
\hline & P-value & & & 0.000 & & \\
\hline
\end{tabular}

Statistically significant (P value: 0.000). So, CK20 expression had a direct correlation with stage of invasive urothelial carcinoma.

Table 5. Correlation of p53 immunoreactivity to tumor grade of non-invasive papillary urothelial carcinoma.

\begin{tabular}{|c|c|c|c|c|c|c|}
\hline \multicolumn{2}{|c|}{ Grade } & \multicolumn{5}{|c|}{ p53 } \\
\hline & & Negative & Weak & Moderate & Strong & Total \\
\hline \multirow{2}{*}{ Low grade } & $\mathrm{N}$ & 5 & 3 & 7 & 3 & 18 \\
\hline & $\%$ & 27.78 & 16.67 & 38.89 & 16.67 & 100.00 \\
\hline \multirow{2}{*}{ High grade } & $\mathrm{N}$ & 0 & 0 & 2 & 5 & 7 \\
\hline & $\%$ & 0.00 & 0.00 & 28.57 & 71.43 & 100.00 \\
\hline \multirow{2}{*}{ Total } & $\mathrm{N}$ & 5 & 3 & 9 & 8 & 25 \\
\hline & $\%$ & 20.00 & 12.00 & 36.00 & 32.00 & 100.00 \\
\hline \multirow{2}{*}{ Chi-square } & $\mathrm{X}^{2}$ & & & 7.983 & & \\
\hline & P-value & & & 0.046 & & \\
\hline
\end{tabular}

Statistically significant (P-value: 0.046). So, p53 expression had a direct correlation with the grade of non-invasive urothelial carcinomas.

Table 6. Correlation of p53 immunoreactivity to tumor grade of invasive urothelial carcinoma.

\begin{tabular}{|c|c|c|c|c|c|c|}
\hline \multirow{2}{*}{\multicolumn{2}{|c|}{ Grade }} & \multicolumn{5}{|c|}{ p53 } \\
\hline & & Negative & Weak & Moderate & Strong & Total \\
\hline \multirow{2}{*}{ Grade I } & $\mathrm{N}$ & 2 & 4 & 2 & 0 & 8 \\
\hline & $\%$ & 25.00 & 50.00 & 25.00 & 0.00 & 100.00 \\
\hline \multirow{2}{*}{ Grade II } & $\mathrm{N}$ & 18 & 20 & 59 & 14 & 111 \\
\hline & $\%$ & 16.22 & 18.02 & 53.15 & 12.61 & 100.00 \\
\hline \multirow{2}{*}{ Grade III } & $\mathrm{N}$ & 5 & 4 & 12 & 20 & 41 \\
\hline & $\%$ & 12.20 & 9.76 & 29.27 & 48.78 & 100.00 \\
\hline \multirow{2}{*}{ Grade IV } & $\mathrm{N}$ & 2 & 0 & 0 & 0 & 2 \\
\hline & $\%$ & 100.00 & 0.00 & 0.00 & 0.00 & 100.00 \\
\hline \multirow{2}{*}{ Total } & $\mathrm{N}$ & 27 & 28 & 73 & 34 & 162 \\
\hline & $\%$ & 16.67 & 17.28 & 45.06 & 20.99 & 100.00 \\
\hline \multirow{2}{*}{ Chi-square } & $X^{2}$ & & & 36.516 & & \\
\hline & P-value & & & 0.000 & & \\
\hline
\end{tabular}

Statistically significant (P value: 0.000). So, p53 expression had a direct correlation with grade of invasive urothelial carcinoma. 
Urothelial CIS (5 cases): p63 was strongly expressed throughout of the urothelium in 4 cases, and in basal layers with gradual decrease towards the epithelial surface in 1case.

Non-invasive papillary carcinoma (25 cases): p63 was expressed in all cases and ranged from moderate to strong, see (Table 8).

Invasive urothelial carcinoma (162 cases): p63 was expressed in 134 cases (82.71\%), strong in 28 (17.28 \%), moderate in 63 (38.89\%) and weak in 43 (26.54 \%), see (Table 9 \& Table 10) and (Figure 9).

Table 7. Correlation of p53 immunoreactivity to tumor stage of invasive urothelial carcinoma.

\begin{tabular}{|c|c|c|c|c|c|c|}
\hline \multicolumn{2}{|c|}{ Stage } & \multicolumn{5}{|c|}{ p53 } \\
\hline & & Negative & Weak & Moderate & Strong & Total \\
\hline \multirow{2}{*}{ pTa } & No. & 5 & 3 & 9 & 8 & 25 \\
\hline & $\%$ & 20.00 & 12.00 & 36.00 & 32.00 & 100.00 \\
\hline \multirow{2}{*}{ pT1 } & No. & 14 & 13 & 37 & 5 & 69 \\
\hline & $\%$ & 20.29 & 18.84 & 53.62 & 7.25 & 100.00 \\
\hline \multirow{2}{*}{ pT2 } & No. & 12 & 14 & 28 & 8 & 62 \\
\hline & $\%$ & 19.35 & 22.58 & 45.16 & 12.90 & 100.00 \\
\hline \multirow{2}{*}{ pT3 } & No. & 1 & 1 & 8 & 16 & 26 \\
\hline & $\%$ & 3.85 & 3.85 & 30.77 & 61.54 & 100.00 \\
\hline \multirow{2}{*}{ pT4 } & No. & 0 & 0 & 0 & 5 & 5 \\
\hline & $\%$ & 0.00 & 0.00 & 0.00 & 100.00 & 100.00 \\
\hline \multirow{2}{*}{ Total } & No. & 32 & 31 & 82 & 42 & 187 \\
\hline & $\%$ & 17.11 & 16.58 & 43.85 & 22.46 & 100.00 \\
\hline \multirow{2}{*}{ Chi-square } & $\mathrm{X}^{2}$ & & & 53.364 & & \\
\hline & P-value & & & 0.000 & & \\
\hline
\end{tabular}

Statistically significant (P value: 0.000). So, p53 expression had a direct correlation with stage of urothelial carcinoma.

Table 8. Percentage of positive p63 cells in correlation with the grade of non-invasive papillary urothelial carcinoma.

\begin{tabular}{cccccc} 
& & & & & \\
& \% of cells & & & T-test \\
\hline Grade (non-invasive carcinoma) & No. & Mean & SD & P-value \\
\hline Low grade & 18 & 90.278 & 5.809 & 7.481 \\
High grade & 7 & 65.000 & 11.180 & $<0.001^{*}$ \\
\hline
\end{tabular}

Statistically significant (P-value: <0. 001). So, p63 expression had an inverse correlation with grade of non invasive urothelial carcinomas.

Table 9. Correlation of p63 immunoreactivity to tumor grade of invasive urothelial carcinoma.

\begin{tabular}{|c|c|c|c|c|c|c|}
\hline \multirow{2}{*}{\multicolumn{2}{|c|}{ Grade }} & \multicolumn{5}{|c|}{ p63 } \\
\hline & & Negative & Weak & Moderate & Strong & Total \\
\hline \multirow{2}{*}{ Grade I } & $\mathrm{N}$ & 0 & 0 & 1 & 7 & 8 \\
\hline & $\%$ & 0.00 & 0.00 & 12.50 & 87.50 & 100.00 \\
\hline \multirow{2}{*}{ Grade II } & $\mathrm{N}$ & 9 & 26 & 55 & 21 & 111 \\
\hline & $\%$ & 8.11 & 23.42 & 49.55 & 18.92 & 100.00 \\
\hline \multirow{2}{*}{ Grade III } & $\mathrm{N}$ & 17 & 17 & 7 & 0 & 41 \\
\hline & $\%$ & 41.46 & 41.46 & 17.07 & 0.00 & 100.00 \\
\hline \multirow{2}{*}{ Grade IV } & $\mathrm{N}$ & 2 & 0 & 0 & 0 & 2 \\
\hline & $\%$ & 100.00 & 0.00 & 0.00 & 0.00 & 100.00 \\
\hline \multirow{2}{*}{ Total } & $\mathrm{N}$ & 28 & 43 & 63 & 28 & 162 \\
\hline & $\%$ & 17.28 & 26.54 & 38.89 & 17.28 & 100.00 \\
\hline \multirow{2}{*}{ Chi-square } & $\mathrm{X}^{2}$ & & & 71.168 & & \\
\hline & P-value & & & 0.000 & & \\
\hline
\end{tabular}

Statistically significant (P value: 0.000). So, p63 expression had an inverse correlation with grade of invasive urothelial carcinomas. 
Table 10. Correlation of p63 immunoreactivity to tumor stage of invasive urothelial carcinoma.

\begin{tabular}{|c|c|c|c|c|c|c|}
\hline \multicolumn{2}{|c|}{ Stage } & \multicolumn{5}{|c|}{ p63 } \\
\hline & & Negative & Weak & Moderate & Strong & Total \\
\hline \multirow{2}{*}{ pTa } & $\mathrm{N}$ & 0 & 0 & 1 & 24 & 25 \\
\hline & $\%$ & 0.00 & 0.00 & 4.00 & 96.00 & 100.00 \\
\hline \multirow{2}{*}{ pT1 } & $\mathrm{N}$ & 3 & 11 & 30 & 25 & 69 \\
\hline & $\%$ & 4.35 & 15.94 & 43.48 & 36.23 & 100.00 \\
\hline \multirow{2}{*}{ pT2 } & $\mathrm{N}$ & 13 & 18 & 28 & 3 & 62 \\
\hline & $\%$ & 20.97 & 29.03 & 45.16 & 4.84 & 100.00 \\
\hline \multirow{2}{*}{ pT3 } & $\mathrm{N}$ & 7 & 14 & 5 & 0 & 26 \\
\hline & $\%$ & 26.92 & 53.85 & 19.23 & 0.00 & 100.00 \\
\hline \multirow{2}{*}{ pT4 } & $\mathrm{N}$ & 5 & 0 & 0 & 0 & 5 \\
\hline & $\%$ & 100.00 & 0.00 & 0.00 & 0.00 & 100.00 \\
\hline \multirow{2}{*}{ Total } & $\mathrm{N}$ & 28 & 43 & 64 & 52 & 187 \\
\hline & $\%$ & 14.97 & 22.99 & 34.22 & 27.81 & 100.00 \\
\hline \multirow{2}{*}{ Chi-square } & $\mathrm{X}^{2}$ & & & 134.741 & & \\
\hline & P-value & & & 0.000 & & \\
\hline
\end{tabular}

Statistically significant (P value: 0.000). So, p63 expression had an inverse correlation with stage of invasive urothelial carcinomas.

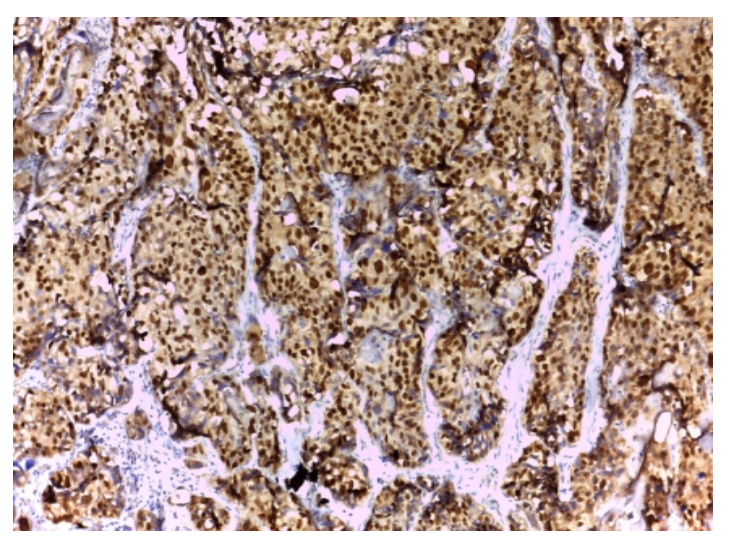

Figure 9. Invasive urothelial carcinoma grade II strongly positive for $\mathrm{p} 63(\mathrm{DAB} \times 150)$.

\section{Discussion}

The aim of this work is to evaluate the role of CK20, p53 and p63 in differentiation between urothelial hyperplasia, dysplasia, and grade and stage of the urothelial carcinoma.

In the current study, CK20 was expressed in all cases of normal urothelium and the expression was limited to the superficial umbrella cell layer and the reaction was moderate in most of cases, similar findings were reported by Southgate et al., (1999) [14] who noted that normal urothelium showed CK20 cytoplasmic immunoreactivity in the superficial umbrella cell layer and this was named the normal CK20 expression pattern. Castillo-Martin et al., (2010) [15] studied molecular pathways of urothelial development and bladder tumorigenesis and found that umbrella cells are characterized by expression of CK18 and CK20.

In this work, scattered CK20 immunoreactivity was demonstrated in all cases of dysplasia and the reaction was documented in the upper two thirds of the urothelial thickness in $85.7 \%$ of cases, it involved the whole thickness of the urothelium in $14.3 \%$. these findings are parallel to those of Harnden et al., (1996) [16] who found that the expression of CK20 was restricted to superficial "umbrella" cells, even in the presence of severe 
inflammation while in the vast majority of cases of dysplasia, it was seen at least focally with positive expression in all layers of the urothelium.

In this work, all cases of CIS showed strong CK20 positivity in the majority of malignant cells and the positivity was through the full thickness of the urothelium. Similar findings were reported by Mallofré et al., 2003 [8], (McKenney et al., 2001, Yin et al., 2006 \& Nese et al., 2009) [17]-[19] who found intense CK20 positivity in the vast majority of cases of urothelial CIS in the majority of malignant cells through the full thickness of the urothelium.

In the current study, CK20 was expressed in $82.89 \%$ of the cases of urothelial carcinoma and the reaction was strong in $30.48 \%$, moderate in $41.71 \%$ and weak in $10.7 \%$ of cases. Similar findings were reported by Moll et al., 1992, Miettinen et al., 1995 and Wang et al., 1995) [20]-[22] who found the expression of CK20 in different human cancers and found that the majority of cases of urothelial carcinoma showed positive CK20 expression.

In this work, p53 was not expressed in non-neoplastic urothelium (including normal and hyperplastic urothelium) apart from occasional weak positivity in the basal and intermediate layers in some cases, these findings are parallel to those of Mallofré et al., 2003 [8], Yildiz et al., 2009) [10], (McKenney et al., 2001 [17] \& Kalantari and Ahmadnia, 2007 [23] who found that p53 immunoreactivity in normal urothelium ranged from negative to weak and patchy and in reactive urothelium, p53 expression was predominantly negative with occasional weak positivity in the basal and intermediate cells. These results support the view that the absence of p53 in urothelium points to its non neoplastic nature. However, Soukup et al., (2007) [24] found p53 positivity in some cases of non-tumor mucosa of urinary bladder in patients with superficial bladder cancer. These cases with p53 positivity in non-tumor mucosa showed higher recurrence rate than that with normal p53 negative non-tumor mucosa.

In this study, p53 positivity of moderate to strong intensity was documented in all the studied cases of dysplasia and the expression was scattered throughout the urothelium. Similar finding was reported by Yildiz et al., (2009) [10] who found that most of the cases of dysplasia had p53 positivity in scattered cells through the urothelium.

Many workers Mallofré et al., 2003 [8], Yildiz et al., 2009) [10], (McKenney et al., 2001 [17] \& Nese et al., 2009 [19] demonstrated strong p53 positivity in the majority of cases of urothelial CIS in most of malignant cells throughout the urothelium, an expression similar to that found in the current study. Contrary to these findings are those of Nakopoulou et al., (1998) [25] who did not demonstrate p53 expression in the dysplastic urothelia examined.

In the current study, p53 was expressed in $82.89 \%$ of the cases of urothelial carcinoma and the reaction was strong in $22.46 \%$, moderate in $43.85 \%$ and weak in $16.58 \%$ of cases. Similar findings were reported by (Thomas et al., 1994, Burkhard et al., 1997, Grossman et al., 1998, Uchida et al., 2002, Babjuk et al., 2003 \& Venyo et al., 2010) [26]-[31] who found p53 expression in the majority of cases of urothelial carcinoma.

In the current study, in all cases of dysplasia and 1case of CIS, p63 expression showed a maximum intense reaction in the nuclei of basal epithelial cells, which was gradually diminished towards the epithelial surface. Most (80\%) of the cases of CIS showed strong positivity for p63 in all layers of the urothelium.

Many studies Di Como et al., 2002 [7], Kaufmann et al., 2001 [11], (Yang et al., 1998, Koga et al., 2003, Karni-Schmidt et al., 2011 \& Pignon et al., 2013) [32]-[35] demonstrated that non-neoplastic urothelium (including normal and reactive hyperplastic urothelium) showed strong positive nuclear immunoreactivity to p63 in entire basal and parabasal cells but immunoreactivity was undetectable in umbrella cells, an expression similar to that found in all studied cases of the non-neoplastic urothelium in the current study.

In the current study, p63 was expressed in $85.02 \%$ of the cases of urothelial carcinoma and the reaction was strong in $27.81 \%$, moderate in $34.22 \%$ and weak in $22.99 \%$ of cases. This agrees with the results of Kaufmann et al., (2001) [11] who found that the majority of cases (more than 70\%) of urothelial carcinoma were p63 positive. This agrees also with the results of Di Como et al., (2002) [7] who studied the expression of p63 in some different human normal and tumor tissues and showed that p63 is expressed in most of the cases of urothelial carcinoma.

In the current study, p63 was expressed in all cases of non-invasive papillary urothelial carcinoma and the reaction ranged from moderate to strong in most of the cells. Similar findings were reported by Urist et al., (2002) [36] who found that low-grade papillary superficial bladder tumors expressed p63 in 93\% of tumor cells. However in the high-grade superficial tumors, there was a significant reduction in p63 positivity to $68 \%$.

In the current study, p63 was expressed in $83.33 \%$ of the cases of invasive urothelial carcinoma and the reac- 
tion was strong in $20.99 \%$, moderate in $45.06 \%$ and weak in $17.28 \%$ of cases, these findings are in agreement with Chuang et al., (2007) \& Srinivasan and Parwani (2011) [37]-[38] who showed that urothelial carcinomas usually show p63 positivity while prostate carcinomas always show p63 negativity. Thus p63 expression can be used as a useful tool in distinguishing urothelial carcinomas from prostate carcinoma.

\section{Conclusion}

We conclude that there is a role of CK20, p53 and p63 in differentiating non-neoplastic lesions, dysplastic lesions and urothelial carcinoma, and these markers can be used as potential predictors of biologic behavior of urothelial carcinoma. We recommended performing many prospective studies with clinical correlation between these markers and the progression of urothelial tumors with large series of patients.

\section{References}

[1] Eble, J.N., Sauter, G., Epstein, J.I. and Sesterhenn, I.A. (2004) World Health Organization Classification of Tumors. Pathology and Genetics of Tumors of the Urinary System and Male Genital Organs. IARC Press, Lyon.

[2] Sangeeta, D., Lim, S.D., Jimenez, R.E., Chun, T., Keane, T.E., McKenney, J.K., Pompa, A.Z., Cohen, C., Young, R.H. and Amin, M.B. (2000) Relationship of Cytokeratin 20 and CD44 Protein Expression with WHO/ISUP Grade in pTa and pT1 Papillary Urothelial Neoplasia. Modern Pathology, 13, 1315-1323. http://dx.doi.org/10.1038/modpathol.3880241

[3] Şentürk, N., Aybek, Z. and Düzcan, E (2010) Ki-67, p53, Bcl-2 and Bax Expression in Urothelial Carcinomas of Urinary Bladder. Turkish Journal of Pathology, 26, 025-030.

[4] Pasin, E., Josephson, D.Y., Mitra, A.P., Cote, R.J. and Stein, J.P. (2008) Superficial Bladder Cancer: An Update on Etiology, Molecular Development, Classification, and Natural History. Reviews in Urology, 10, 1.

[5] Ramos, D., Navarro, S., Villamón, R., Gil-Salom, M. and Llombart-Bosch, A. (2003) Cytokeratin Expression Patterns in Low-Grade Papillary Urothelial Neoplasms of the Urinary Bladder. Cancer, 97, 1876-1883.

http://dx.doi.org/10.1002/cncr.11265

[6] Cina, S.J., Epstein, J.I., Endrizzi, J.M., Harmon, W.J., Seay, T.M. and Schoenberg, M.P. (2001) Correlation of Cystoscopic Impression with Histologic Diagnosis of Biopsy Specimens of the Bladder. Human Pathology, 32, 630-637. http://dx.doi.org/10.1053/hupa.2001.24999

[7] Di Como, C.J., Urist, M.J., Babayan, I., Drobnjak, M., Hedvat, C.V., Teruya-Feldstein, J., Pohar, K., Hoos, A. and Cordon-Cardo, C. (2002) p63 Expression Profiles in Human Normal and Tumor Tissues. Clinical Cancer Research, 8, 494-501.

[8] Mallofré, C., Castillo, M., Morente, V. and Solé, M. (2003) Immunohistochemical Expression of CK20, p53, and Ki-67 as Objective Markers of Urothelial Dysplasia. Modern Pathology, 16, 187-191. http://dx.doi.org/10.1097/01.MP.0000056628.38714.5D

[9] Stepan, A., Mărgăritescu, C.L., Simionescu, C. and Ciurea, R. (2009) E-cadherin and p63 Immunoexpression in Dysplastic Lesions and Urothelial Carcinomas of the Bladder. Romanian Journal of Morphology and Embryology, 50, 461465.

[10] Yildiz, I.Z., Recavarren, R., Armah, H.B., Bastacky, S., Dhir, R. and Parwani, A.V. (2009) Utility of a Dual Immunostain Cocktail Comprising of p53 and CK20 to Aid in the Diagnosis of Non-Neoplastic and Neoplastic Bladder Biopsies. Diagnostic Pathology, 4, 35. http://dx.doi.org/10.1186/1746-1596-4-35

[11] Kaufmann, O., Fietze, E., Mengs, J. and Dietel, M. (2001) Value of p63 and Cytokeratin 5/6 as Immunohistochemical Markers for the Differential Diagnosis of Poorly Differentiated and Undifferentiated Carcinomas. American Journal of Clinical Pathology, 116, 823-830. http://dx.doi.org/10.1309/21TW-2NDG-JRK4-PFJX

[12] Stigler, S. (2008) Fisher and the 5\% Level. Chance, 21, 12. http://dx.doi.org/10.1007/s00144-008-0033-3

[13] Dallal, G.E. (2012) The Little Handbook of Statistical Practice. Tufts University Press, Boston.

[14] Southgate, J., Harnden, P. and Trejdosiewicz, L.K. (1999) Cytokeratin Expression Patterns in Normal and Malignant Urothelium: A Review of the Biological and Diagnostic Implications. Histology and Histopathology, 14, 657-664.

[15] Castillo-Martin, M., Domingo-Domenech, J., Karni-Schmidt, O., Matos, T. and Cordon-Cardo, C. (2010) Molecular Pathways of Urothelial Development and Bladder Tumorigenesis. Urologic Oncology, 28, 401-408. http://dx.doi.org/10.1016/j.urolonc.2009.04.019

[16] Harnden, P., Eardley, I., Joyce, A.D. and Southgate, J. (1996) Cytokeratin 20 as an Objective Marker of Urothelial Dysplasia. British Journal of Urology, 78, 870-875. http://dx.doi.org/10.1046/j.1464-410X.1996.23511.x 
[17] McKenney, J.K., Gomez, J.A., Desai, S., Lee, M.W. and Amin, M.B. (2001) Morphologic Expressions of Urothelial Carcinoma in Situ: A Detailed Evaluation of Its Histologic Patterns with Emphasis on Carcinoma in Situ with Microinvasion. The American Journal of Surgical Pathology, 25, 356-362. http://dx.doi.org/10.1097/00000478-200103000-00010

[18] Yin, H., He, Q., Li, T. and Leong, A.S. (2006) Cytokeratin 20 and Ki-67 to Distinguish Carcinoma in Situ from Flat Non-Neoplastic Urothelium. Applied Immunohistochemistry Molecular Morphology, 14, 260-265. http://dx.doi.org/10.1097/00129039-200609000-00002

[19] Nese, N., Gupta, R., Bui, M.H. and Amin, M.B. (2009) Carcinoma in Situ of the Urinary Bladder: Review of Clinicopathologic Characteristics with an Emphasis on Aspects Related to Molecular Diagnostic Techniques and Prognosis. Journal of the National Comprehensive Cancer Network, 7, 48-57.

[20] Moll, R., Lowe, A., Laufer, J. and Franke, W. (1992) Cytokeratin 20 in Human Carcinomas. A New Histodiagnostic Marker Detected by Monoclonal Antibodies. American Journal of Pathology, 140, 427-447.

[21] Miettinen, M. (1995) Keratin 20: Immunohistochemical Marker for Gastrointestinal, Urothelial and Merkel Cell Carcinomas. Modern Pathology, 8, 384-388.

[22] Wang, N.P., Zee, S., Zarbo, R.J., Bacchi, C.E. and Gown, A.M. (1995) Coordinate Expression of Cytokeratins 7 and 20 Defines Unique Subsets of Carcinomas. Applied Immunohistochemistry, 113, 383-388.

[23] Kalantari, M. and Ahmadnia, H. (2007) p53 Overexpression in Bladder Urothelial Neoplasms New Aspect of World Health Organization/International Society of Urological Pathology Classification. Urology Journal, 4, 111-115.

[24] Soukup, V., Babjuk, M., Dusková, J., Pesl, M., Szakácsova, M., Zámefnik, L. and Dvorácek, J. (2007) The p53 Positivity in Non-Tumor Mucosa in Patients with Superficial Urinary Bladder Cancer. Casopis Lékaru Ceských, 146, 6367.

[25] Nakopoulou, L., Vourlakou, C., Zervas, A., Tzonou, A., Gakiopoulou, H. and Dimopoulos, M.A. (1998) The Prevalence of Bcl-2, p53 and Ki-67 Immunoreactivity in Transitional Cell Bladder Carcinomas and Their Clinicopathologic Correlates. Human Pathology, 29, 146-154. http://dx.doi.org/10.1016/S0046-8177(98)90225-8

[26] Thomas, D.J., Robinson, M.C., Charlton, R., Wilkinson, S., Shenton, B.K. and Neal, D.E. (1994) p53 Expression, Ploidy and Progression in pT1 Transitional Cell Carcinoma of the Bladder. British Journal of Urology, 73, 533-537. http://dx.doi.org/10.1111/j.1464-410X.1994.tb07639.x

[27] Burkhard, F.C., Markwalder, R., Thalmann, G.N. and Studer, U.E. (1997) Immunohistochemical Determination of p53 over Expression: An Easy and Readily Available Method to Identify Progression in Superficial Bladder Cancer. Urological Research, 25, S31-S35. http://dx.doi.org/10.1007/BF00942045

[28] Grossman, H.B., Liebert, M., Antelo, M., Dinney, C.P., Hu, S., Palmer, J.L. and Benedict, W.F. (1998) p53 and RB Expression Predict Progression in T1 Bladder Cancer. Clinical Cancer Research, 4, 829-834.

[29] Uchida, T., Minei, S., Gao, J.P., Wang, C., Satoh, T. and Baba, S. (2002) Clinical Significance of p53, MDM2 and Bcl-2 Expression in Transitional Cell Carcinoma of the Bladder. Oncology Reports, 9, 253-259.

[30] Babjuk, M., Soukup, V., Mares, J., Duskova, J., Solace, Z., Trove, M., Pecan, L., Divorce, J., Hans, T., Novara, R., Novak, J. and Povýsil, C. (2003) The Expression of PAX5, p53 Immunohistochemistry and p53 Mutation Analysis in Superficial Bladder Carcinoma Tissue. Correlation with Pathological Findings and Clinical Outcome. International Urology and Nephrology, 34, 495-501. http://dx.doi.org/10.1023/A:1025652203472

[31] Venyo, A., Greenwood, H. and Maloney, D. (2010) The Expression of p53 in Human Urothelial Carcinoma. Webmed Central Urology, 1, 1-12.

[32] Yang, A., Kaghad, M., Wang, Y., Gillett, E., Fleming, M.D., Dötsch, V., Andrews, N.C., Caput, D. and McKeon, F. (1998) p63, a p53 Homolog at 3q27-29, Encodes Multiple Products with Transactivation, Death-Inducing and Dominant-Negative Activities. Molecular Cell, 2, 305-316. http://dx.doi.org/10.1016/S1097-2765(00)80275-0

[33] Koga, F., Kawakami, S., Kumagai, J., Takizawa, T., Ando, N., Arai1, G., Kageyama, Y. and Kihara, K. (2003) Impaired $\triangle$ Np63 Expression Associates with Reduced $\beta$-Catenin and Aggressive Phenotypes of Urothelial Neoplasms. British Journal of Cancer, 88, 740-747. http://dx.doi.org/10.1038/sj.bjc.6600764

[34] Karni-Schmidt, O., Castillo-Martin, M., HuaiShen, T., Gladoun, N., Domingo-Domenech, J., Sanchez-Carbayo, M., Li, Y., Lowe, S., Prives, C. and Cordon-Cardo, C. (2011) Distinct Expression Profiles of p63 Variants during Urothelial Development and Bladder Cancer Progression. The American Journal of Pathology, 178, 159-165. http://dx.doi.org/10.1016/j.ajpath.2010.11.061

[35] Pignon, J.C., Grisanzio, C., Geng, Y., Song, J., Shivdasani, R.A. and Signoretti, S. (2013) p63-Expressing Cells Are the Stem Cells of Developing Prostate, Bladder and Colorectal Epithelia. Proceedings of the National Academy of Sciences of the United States of America, 110, 8105-8110. http://dx.doi.org/10.1073/pnas.1221216110

[36] Urist, M.J., Di Como, C.J., Lu, M.L., Charytonowicz, E., Verbel, D., Crum, C.P., Ince, T.A., McKeon, F.D. and Cor- 
don-Cardo, C. (2002) Loss of p63 Expression Is Associated with Tumor Progression in Bladder Cancer. The American Journal of Pathology, 161, 1199-1206. http://dx.doi.org/10.1016/S0002-9440(10)64396-9

[37] Chuang, A.Y., DeMarzo, A.M., Veltri, R.W., Sharma, R.B., Bieberich, C.J. and Epstein, J.I. (2007) Immunohistochemical Differentiation of High-Grade Prostate Carcinoma from Urothelial Carcinoma. The American Journal of Surgical Pathology, 31, 1246-1255. http://dx.doi.org/10.1097/PAS.0b013e31802f5d33

[38] Srinivasan, M. and Parwani, A.V. (2011) Diagnostic Utility of p63/P501S Double Sequential Immunohistochemical Staining in Differentiating Urothelial Carcinoma from Prostate Carcinoma. Diagnostic Pathology, 6, 67. http://dx.doi.org/10.1186/1746-1596-6-67 
Scientific Research Publishing (SCIRP) is one of the largest Open Access journal publishers. It is currently publishing more than 200 open access, online, peer-reviewed journals covering a wide range of academic disciplines. SCIRP serves the worldwide academic communities and contributes to the progress and application of science with its publication.

Other selected journals from SCIRP are listed as below. Submit your manuscript to us via either submit@scirp.org or Online Submission Portal.
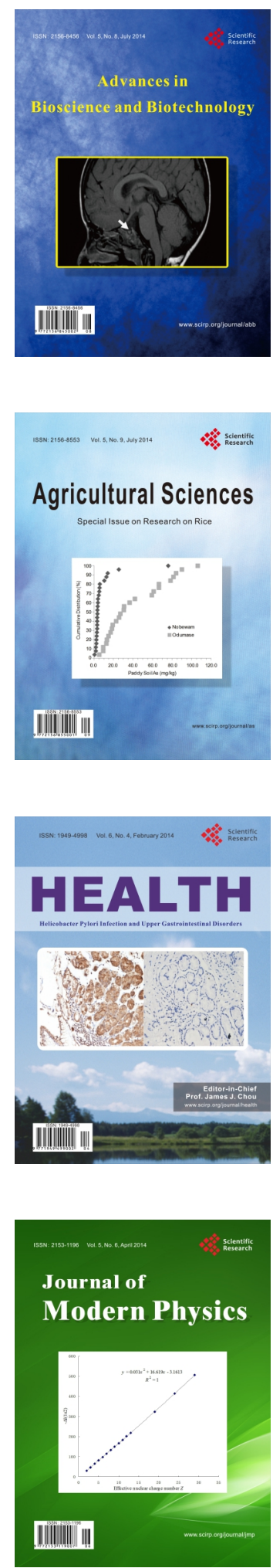
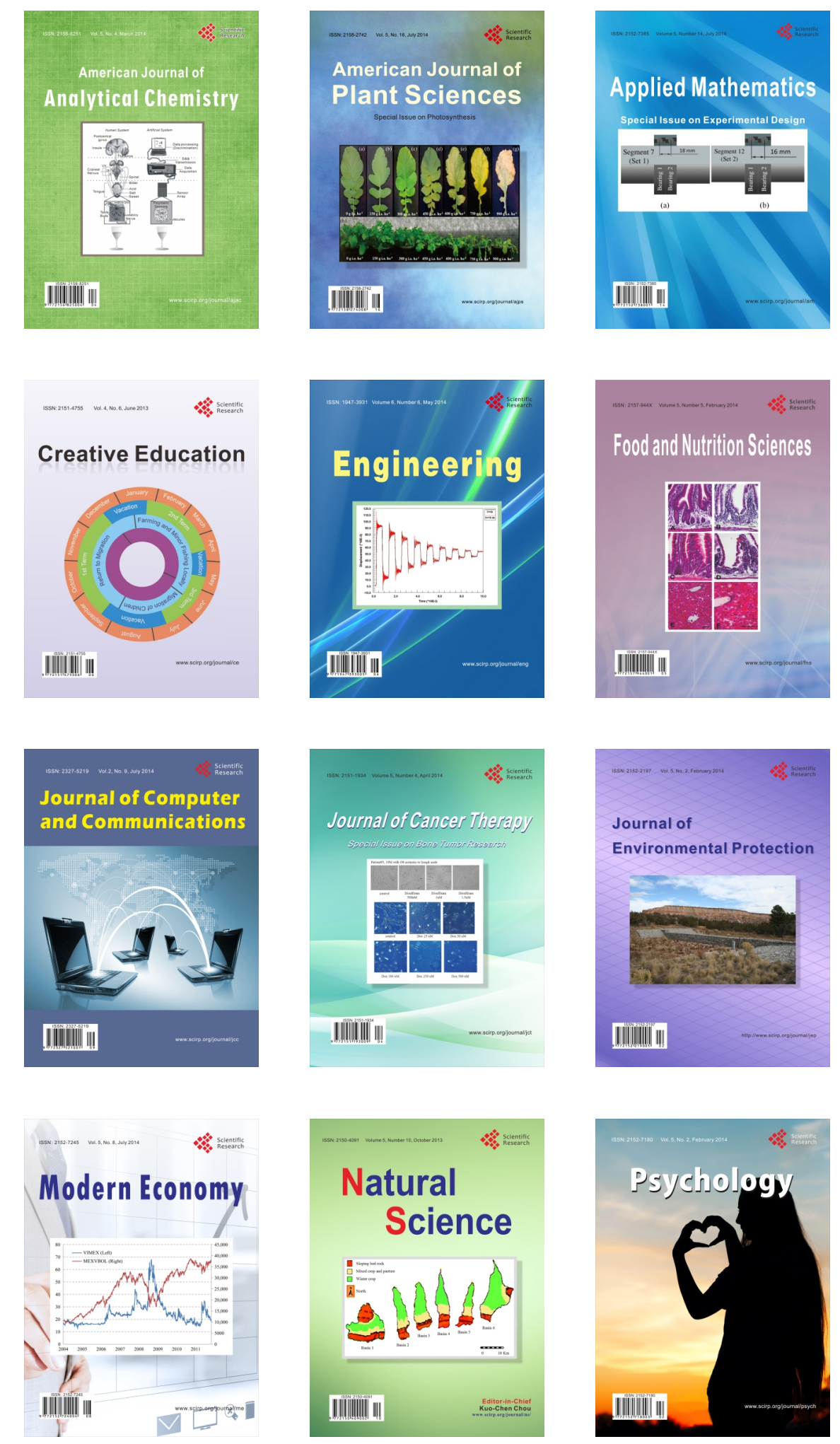